\title{
Expression of CXCL12 and CXCL14 during eye development in Chick and Mouse
}

\author{
Ana F. Ojeda, Ravi P. Munjaal, and Peter Y. Lwigale* \\ Department of Biochemistry and Cell Biology, Rice University, Houston, TX.
}

\begin{abstract}
Vertebrate eye development is a complex multistep process coordinated by signals from the lens, optic cup and periocular mesenchyme. Although chemokines are increasingly being recognized as key players in cell migration, proliferation, and differentiation during embryonic development, their potential role during eye development has not been examined. In this study, we demonstrate by section in situ hybridization that CXCL12 and CXCL14 are expressed during ocular development. CXCL12 is expressed in the periocular mesenchyme, ocular blood vessels, retina, and eyelid mesenchyme, and its expression pattern is conserved between chick and mouse in most tissues. Expression of $C X C L 14$ is localized in the ocular ectoderm, limbal epithelium, scleral papillae, eyelid mesenchyme, corneal keratocytes, hair follicles, and retina, and it was only conserved in the upper eyelid ectoderm of chick and mouse. The unique and non-overlapping patterns of $C X C L 12$ and $C X C L 14$ expression in ocular tissues suggest that these two chemokines may interact and have important functions in cell proliferation, differentiation and migration during eye development.
\end{abstract}

\section{Keywords}

Cornea; limbal epithelium; eyelid; nictitating membrane; scleral ossicles; retina

\section{INTRODUCTION}

Chemokines are a large family of small-secreted chemoattractant cytokines that function in many physiological and pathological processes. Although initially identified as inducers of leukocyte migration during inflammatory response (Wong and Fish, 2003; Kiefer and Siekmann, 2011), recent studies have shown that chemokines are involved in tumor development, neurodegenerative diseases, angiogenesis, and embryogenesis (Rostene et al., 2007; Olesnicky et. al., 2009; Banisadr et al., 2011; Kiefer and Siekmann, 2011). Despite increasing evidence of the involvement of CXCL12 (stromal cell-derived fator-1, SDF-1) and CXCL14 (BRAK, Scyba, or MIP-2y) in non-immune processes such as cell migration, proliferation, and differentiation, very little is known about their involvement in eye development.

\footnotetext{
(C) 2013 Elsevier B.V. All rights reserved.

*Corresponding author: Dr. Peter Y. Lwigale, Rice University, 6100 Main St., Houston, TX 77025, Tel:(713) 348-6785, Fax: (713) 348-5154,1wigale@rice.edu.

Publisher's Disclaimer: This is a PDF file of an unedited manuscript that has been accepted for publication. As a service to our customers we are providing this early version of the manuscript. The manuscript will undergo copyediting, typesetting, and review of the resulting proof before it is published in its final citable form. Please note that during the production process errors may be discovered which could affect the content, and all legal disclaimers that apply to the journal pertain.
} 
CXCL12 signaling mediated by the receptors CXCR4 and/or CXCR7 plays an important role during hematopoiesis, angiogenesis, and in the migration of germ cells, neural crest cells, neural precursors, and limb progenitor cells (Lazarini et al., 2003; Stebler et al., 2004; Yusuf et al, 2006; Theveneau et al., 2010; Belmadani et al., 2009). During embryonic development, CXCL12 is expressed in the mesenchyme of the head, limbs, sclerotome, and in regions surrounding major blood vessels, gonads, and mesonephros (Vasyutina et al., 2005; Rehimi et al., 2008; Garcia-Andres and Torres, 2010). Mutations of CXCL12 or CXCR4 in mice are lethal between embryonic day (E)15 and birth, and the embryos have defective neurogenesis, cardiovascular development, and impaired hematopoiesis (Nagasawa et al., 1996; Ma et al., 1998; Zou et al., 1998). Similar defects are observed in CXCR7 deficient mice, although hematopoiesis was normal (Sierro et al., 2007).

Until recent, very little was known about the involvement of CXCL14 in embryonic development and the receptor(s) that mediate its function remain unknown. In adults, CXCL14 is constitutively expressed in normal epithelial tissues such as the breast, kidney, brain, and lungs (Hromas et al., 1999; Meuter and Moser, 2008). During early embryogenesis in chick and mouse, CXCL14 is expressed in the ectoderm, central nervous system, paraxial mesoderm, limbs, and in the trigeminal and dorsal root ganglia (Park et al., 2012; Gordon et al., 2011; Garcia-Andres and Torres, 2010). Other patterns of CXCL14 expression are observed in Xenopus and zebrafish embryos during development of the cement gland, otic vesicle, dorsal retina, and in migratory cranial neural crest cells and neuromasts of the lateral line (Park et al., 2009; Long et al., 2000). Although CXCL14 is a chemoattractant for immune cells (Kurth et al., 2001; Shellenberger et al., 2004; Tanegashima et al., 2010), CXCL14 deficient mice do not show severe defects in the immune system (Meuter et al., 2007). However, these mice show altered feeding behavior and glucose metabolism that is associated with improved insulin sensitivity (Nara et al., 2007; Tanegashima et al., 2010). CXCL14 inhibits endothelial cell migration in vitro and prevents neovascularization of the cornea in micropocket assays involving various angiogenic factors (Shellenberger et al., 2004). Recent studies have reported that CXCL14 plays a role in differentiation of Langerhans cells in the skin and Schwann cells (Schaerly et al., 2005; Barbaria et al., 2009; Hara and Tanegashima, 2012). Also CXCL14 is upregulated through calcium-calmodulin signaling in a cell density-dependent manner, accompanied by the upregulation of several keratinocyte differentiation markers of epithelial cells (Ikoma et al., 2012).

Vertebrate eye development is a multistep process that involves interactions between cells and tissues from different embryonic origins that result in the formation of a functional organ. At the rudimentary stage, the eye is comprised of the lens vesicle and overlaying ectoderm, the optic cup, and the periocular mesenchyme comprised of neural crest cells and cranial mesoderm. The following events occur during subsequent development of the eye: (1) The lens vesicle forms the lens epithelium and crystalline cells (Cvekl and Mitton, 2010; Ogino et al., 2012); (2) The periocular mesenchyme combines with the overlying ectoderm to form the cornea and the eyelids (Johnston et al., 1979; Hay, 1980; Creuzet et al., 2005; Lwigale et al., 2005); (3) Angioblasts in the periocular region undergo vasculogenesis to form the complex network of limbal blood vessels (Kwiatkowski et al, 2013); (4) The optic cup differentiates into the retinal pigment epithelium and the neuroretina (Venters et al., 2011; Fuhrmann, 2010); and (5) The trigeminal, ciliary, and oculomotor nerves project into the eye to provide sensory and sympathetic innervation (Narayanan and Narayanan, 1978). Signaling between the ocular tissues is essential for cell migration, proliferation, and differentiation that enable the proper formation of a functional eye. Although CXCL12 and CXCL14 have been associated with such cellular events, these chemokines have not been studied during eye development. To determine the potential roles of CXCL12 and CXCL14 during eye development, we studied their expression patterns during the formation of ocular 
tissues. Due to differences between avian (Johnston et al., 1979) and murine (Pei and Rhodin, 1970) eye development, we compared the expression of CXCL12 and CXCL14 between chick and mouse embryos. Our results show that CXCL12 and CXCL14 are expressed in complementary patterns in most tissues during ocular development. Expression of $C X C L 12$ is conserved between chick and mouse in most ocular tissues, whereas CXCL14 expression is only conserved in the upper eyelid ectoderm. The expression patterns of CXCL12 and CXCL14 indicate their potential interaction and involvement in ocular development.

\section{RESULTS AND DISCUSSION}

To analyze the expression of CXCL12 and CXCL14, we performed in situ hybridization on sections through the eyes of chick and mice embryos at different stages of development. For chick we examined embryos between E3-E17. Since our expression data for CXCL12 and CXCL14 in E3 chick eyes confirms previously observed patterns at this stage (GarciaAndres and Torres, 2010), we show data starting at E5. Because eye development in mice is a continuous process with cell proliferation and changes in gene expression persisting into late postnatal stages (Zieske, 2004), we analyzed embryos between E11, postnatal day (P)0, and in some cases, young adults.

\subsection{Expression of $C X C L 12$ and $C X C L 14$ during development of the cornea and iris}

During eye development, periocular neural crest cells migrate between the lens vesicle and the ectoderm to form the cornea. In chick this is a well-coordinated process involving an initial wave of neural crest cell migration from the periocular mesenchyme to the region between the lens and ectoderm (presumptive cornea epithelium) to form the inner most layer of the cornea (the cornea endothelium). This is followed by a second wave of neural crest cell migration between the endothelium and ectoderm to form the cornea stroma (Johnston et al., 1979; Hay, 1980; Creuzet et al., 2005; Lwigale et al., 2005). In mouse, neural crest cells migrate as a single mass between the lens vesicle and ectoderm, then the cells adjacent to the lens differentiate into the cornea endothelium while the rest form the stroma (Pei and Rhodin, 1970; Gage et. al., 2005). Shortly after cornea formation, the periocular neural crest cells and neuroepithelium at the tip of the optic cup coalesce to form the iris.

Expression of $C X C L 12$ in the chick eye is first detected in the periocular mesenchyme at E3 (data not shown and Garcia-Andres and Torres, 2010). By E5, expression of CXCL12 persists in the periocular mesenchyme, and it is also expressed in the newly formed cornea endothelium (Fig. 1A, arrowhead), and blood vessels (Fig. 1A, A', asterisk). At E7 and E12, expression of $C X C L 12$ in the anterior eye is restricted to the periocular region in cells located adjacent to the retinal pigment epithelium, and it remains strong in the iris stroma and blood vessels (Fig. 1B and C). Similarly, in the mouse eye, CXCL12 expression is initially robust in the periocular mesenchyme at E11.5 (Fig. 1G'), but it becomes restricted to the cells adjacent to the retinal pigment epithelium, iris stroma (Fig. 1G-I, arrows) and ocular blood vessels (Fig. 1H, asterisk). Since CXCL12 is involved in migration of neural crest cells (Olesnicky Killian et al., 2009; Kasemeier-Kulesa et al., 2010; Theveneau et al., 2010) and other embryonic cell types (Doitsidou et al., 2002; Vasyutina et al., 2005; Chen et al., 2007; Li and Ransohoff, 2008), its expression by periocular neural crest cells suggests that it may play a similar role during cornea development. Expression of CXCL12 in the forming ocular blood vessels is consistent with its proangiogenic role during vascular development (Yamaguchi et al., 2003; Hiasa et al., 2004). Since CXCL12 is expressed in the limb during myogenesis (Garcia-Andres and Torres, 2010; Hunger et al., 2012), its presence in the iris stroma indicates a possible role during neural crest cell differentiation into iris muscles. 
In contrast to $C X C L 12$ expression, $C X C L 14$ is not expressed in the anterior region of the chick eye by E5 (Fig. 1D). However, by E7 CXCL14 expression is prominent in the cornea stroma (Fig. 1E and E') and coincides with neural crest differentiation into stromal keratocytes (Hay et al., 1979; Hay, 1980; Funderburgh et al., 1986). CXCL14 is also expressed at low levels in the lens epithelium (Fig. 1E, arrowhead). During subsequent development, expression of $C X C L 14$ is restricted to the keratocytes in anterior region of the corneal stroma at E12 (Fig. 1F). By E15, CXCL14 expression is absent in the stroma (data not shown), but it becomes expressed by cells on the surface and tip of the iris, where it persists through E17 (Fig. 1F'). Unlike most of the cranial and limb ectoderm where intense expression of CXCL14 is observed (Garcia-Andres and Torres, 2010; Gordon et al., 2011), it is not expressed in the ectoderm of the presumptive cornea epithelium in chick (Fig. 1DF).

In the mouse, $C X C L 14$ is initially expressed at low levels in the periocular mesenchyme, optic cup, and lens at E14.5 (Fig. 1J). Expression of CXCL14 in the eyelid epithelium is strong at this time and during subsequent development (discussed in detail later). At E16.5 and $\mathrm{P} 0$, expression of $C X C L 14$ is restricted to the cornea epithelium, optic cup, neuroepithelium of the iris, and in the lens epithelium (Fig. 1K and 1L). Expression of CXCL14 in the mouse cornea coincides with the differentiation of the cornea epithelium as indicated by the expression of the epithelial keratin markers, K12 and K14 (Kurpakus et al., 1994; Tanifuji-Terai et al., 2006). Although expression of CXCL14 in the cornea is not conserved between chick and mouse, its presence in the chick corneal stroma and mouse corneal epithelium may indicate a possible role during keratocyte and epithelial cell differentiation, respectively.

\subsection{Expression of $C X C L 14$ in the anterior ocular epithelium during development}

At E7 and during subsequent development of the chick eye, expression of CXCL12 is limited to the blood vessels and periocular mesenchyme adjacent to the retinal pigment epithelium (Fig. 1B and data not shown). The ectoderm spanning the anterior eye region of the chick does not express $C X C L 14$ during early stages of development (Fig. 1D-1F and data not shown). However, by E7 expression of CXCL14 is vivid in the region of the ectoderm (Fig. 2A and 2A') corresponding to the location of the scleral papillae (Coulombre and Coulombre, 1962). Scleral papillae are thickenings in the conjunctival epithelium (Franz-Odendaal and Vickaryous, 2006), that induce the underlying neural crest mesenchyme to form skeletogenic condensations known as scleral ossicles (Coulombre and Coulombre, 1962; Pinto and Hall, 1991). Expression of CXCL14 in the conjunctival epithelium coincides with the time when the mesenchyme becomes competent to induce the formation of scleral papillae in the overlying conjunctival epithelium (Wedlock et al., 1969; Hall, 1981; Duench and Franz-Odendaal, 2012). Section through a scleral papilla at more advanced stage of formation shows expression of $C X C L 14$ in the thickened ectoderm, but it is absent in the superficial cells above the thickest central region (Fig. 2B, asterisk). CXCL14 is expressed at low levels as the scleral papillae increase in size to form a visible outgrowth above the epithelium (Fig. 2C, asterisk). By E11, expression of CXCL14 is absent in this region of the conjunctival epithelium and coincides with the degeneration of the scleral papillae (Murray, 1943; Franz-Odendaal, 2008). Our results show CXCL14 expression as a novel early marker for scleral papillae and suggest that it may play a role in establishing the transient placodal phase of the conjunctival epithelium.

By E12, expression of $C X C L 14$ is strong in another group of conjunctival epithelial cells located in the limbus region adjacent to the cornea epithelium (Fig. 2D and 2D'). By E17, cells expressing CXCL14 are located in the basal cell layer of limbal epithelium near the margin of the cornea epithelium (Fig. 2E and 2E'). Unlike chick, expression of CXCL14 in the mouse is maintained at modest levels in the cornea and conjunctival epithelium during 
development (Fig. 1K and 1L). In adult mouse corneas, CXCL14 is expressed in the basal and wing layers of the epithelium (Fig. 2F and 2G). In the limbal epithelium, CXCL14 expression is maintained at a slightly higher level in comparison to the corneal epithelium (Fig. 2H). In adult eyes, the basal layer of the limbal epithelium contains a reservoir of stem cells that replenish the cornea epithelium (Tseng, 1989; Schlötzer-Schrehardt et al., 2005), but their origin and when they are established is not known. Based on our results, it is possible that $C X C L 14$ plays a role during the formation of the limbal stem cells. Similarly, previous studies have shown that $C X C L 14$ is expressed in regions where stem cells reside in other tissues including the dentate gyrus of the hippocampus (Banisadr et al., 2011), skin epithelial cells (Schaerli et al., 2005; Frick et al., 2011), and at the base of the intestinal crypts (Meuter and Moser, 2008).

\subsection{Expression of CXCL12 and CXCL14 in the eyelids}

The conjunctival epithelium also covers the inner eyelid and the nictitating membrane. The nictitating membrane is a transparent tissue that protects and lubricates the anterior surface of the eye. It exists in reptiles, birds, amphibians, and some mammals, but absent in primates and mice (Stibbe, 1928). The eyelids first appear as mesenchyme filled bumps in the ectoderm at about E7 in chick (Hamburger and Hamilton, 1951) and between E13 and E14 in mouse (Pei and Rhodin, 1970). In chick, the nictitating membrane also appears at about E7 as an additional mesenchyme filled bump adjacent to the eyelid.

Expression of $C X C L 12$ is not detected in the forming chick eyelid at E7 (Fig. 3A). By E8, CXCL12 expression is prominent in the mesenchyme of the eyelid and low in the nictitating membrane (Fig. 3B). At E12, expression of CXCL12 persists in the mid-region of the eyelid mesenchyme (Fig. 3C) that later differentiates into the eyelid muscles (Noden, 1986; Creuzet et al., 2005). At this time only a few cells express $C X C L 12$ in the mid-region of the nictitating membrane (data not shown). CXCL12 is also expressed in the mesenchyme surrounding the feather buds on the eyelids (Fig. 3C').

CXCL14 is strongly expressed in the eyelid ectoderm at E7 (Fig. 3D). This pattern of CXCL14 expression persists in the ectoderm of the eyelid and nictitating membrane at E8 and E12 (Fig. 3E and 3F). Expression of CXCL14 is also observed in a few cells in the midregion of the feather buds and in the surrounding surface ectoderm (Fig. 3F').

In the mouse, $C X C L 12$ is strongly expressed in the mesenchyme located in the mid-region of the eyelid by E14.5 and its intensity decreases towards the edges (Fig. 3G). This pattern of $C X C L 12$ expression persists in the eyelid mesenchyme at E16.5 (Fig. $3 \mathrm{H}$ ) and during later stages of development (data not shown). In contrast, at E14.5 CXCL14 is expressed in the ectoderm of the outer eyelid, but absent in the inner eyelid. CXCL14 is also expressed in the mesenchyme at the anterior region of the eyelid at E14.5 (Fig. 3J), and it persists at low levels in this region at E16.5 (Fig. 3K).

Given that feather buds form at the posterior region of the eyelids in chick but hair follicles are at a relatively early stage of development in the mouse eyelids between E11.5-E16.5, we examined the expression patterns of $C X C L 12$ and $C X C L 14$ in the hair follicles of the whisker pad at E16.5. Although CXCL12 is expressed at low levels in the developing hair follicles (Fig. 3I, dotted lines), it is strong in the surrounding mesenchyme. In contrast, CXCL14 is strongly expressed in the hair follicles (Fig. 3L). Its expression is continuous with the basal layer of the skin and encompasses the outer root sheath, hair bulb (Fig. 3L, arrow) and bulge (Fig. 3L, arrowhead) regions of the hair follicle (Fig. 3L). Expression of CXCL14 in the bulge region of the follicle where hair stem cells reside (Spradling et al., 2001; Wang et al., 2012) further indicates its potential role in stem cell development. 
Our results show that $C X C L 12$ and $C X C L 14$ are expressed in complementary patterns during eyelid development. Expression of $C X C L 12$ in the eyelids is conserved between the chick and mouse at early stages of development but it is restricted in the posterior eyelid mesenchyme of the mouse by E16.5. Therefore CXCL12 may play similar role that occurs at different time in chick and mouse eyelid development. Expression of CXCL14 in the eyelids also appears to be conserved between chick and mouse, with the exception of the inner eyelid epithelium in mouse where it is absent.

\subsection{Expression of CXCL12 and CXCL14 in the retina}

Following the formation of the optic cup, the outer layer becomes the retinal pigmented epithelium (RPE) and an inner layer gives rise to the neural retina (Pei and Rhodin, 1970, Agathocleous and Harris, 2009). After successive proliferation and differentiation, the neural retina is divided into three cellular layers: the outer nuclear layer (ONL) that contains rod and cone photoreceptors; the inner nuclear layer (INL) consisting of horizontal, amacrine, Muller, and bipolar cells; and the ganglion cell layer (GCL) located near the inner surface and comprised of retinal ganglion cells (Chow and Lang, 2001; Bassett and Wallace, 2012).

Expression of CXCL12 in the posterior eye region of chick (Fig. 4A and 4B) and mouse (Fig. 4E and 4F) is restricted to the connective tissue and choroidal blood vessels adjacent to the RPE. A few cells in the anterior most region of the chick INL express $C X C L 12$ at E12 (Fig. 4B) but no expression of $C X C L 12$ was observed in the mouse neuroretina by P0 (Fig. $4 \mathrm{~F})$. Interestingly, a different pattern of $C X C L 12$ expression was observed in the internal limiting membrane (ILM) of the human retina at 2 weeks of gestation and believed to function in vessel assembly (Hasegawa et al., 2008). In addition to its function in angiogenesis, CXCL12 may also contribute to retina development since it promotes the survival of embryonic retinal ganglion cells that express $C X C R 4$ receptor (Chalasani et al., 2003).

Expression of $C X C L 14$ is sparse and diffuse in the chick neural retina at E7 (Fig. 4C). By E12, its expression is restricted to the INL in regions where amacrine and bipolar cells reside, and by a few cells in the GCL layers (Fig. 4C). In the mouse, CXCL14 is broadly expressed in the neural retina at E16.5 (Fig. 4G). By P0, vivid expression of CXCL14 is maintained in the neuroretina (Fig. $4 \mathrm{H}$ ), but it is absent in the developing inner plexiform layer (IPL). All cell layers are formed in young adult mouse retinas and CXCL14 is expressed in the inner boundary of the INL populated by amacrine cells (Doh et al., 2010; Bassett and Wallace, 2012), and in the GCL (Fig H, inset). Our results show that retina expression of $C X C L 14$ is conserved between chick and mouse. The asymmetric distribution of CXCL14 in developing and adult retinas suggests a potential role in positioning, differentiation and/or maintenance of retinal cells in specific layers.

\section{CONCLUSIONS}

Our results revealed novel expression patterns of CXCL12 and CXCL14 and suggest that these two chemokines may play essential roles during ocular development in chick and mouse. Expression of $C X C L 12$ in the ocular mesenchyme and blood vessels was conserved between chick and mouse suggesting similar function during neural crest cell differentiation into muscles of the eyelid and iris, and during ocular vasculogenesis in both species. Chickspecific expression of $C X C L 12$ in the amacrine cells of the retina indicates potential role in cell proliferation or differentiation. In contrast, $C X C L 14$ was expressed in the ocular ectoderm and corresponded with the formation of the scleral papillae and hair follicles, and it was localized in the basal layer of the limbal epithelium where stem cells reside. The observed expression patterns indicate potential involvement of CXCL14 in cell 
differentiation and proliferation in the ocular epithelium. $C X C L 14$ expression in the eyelid mesenchyme and cornea suggests a possible function in neural crest differentiation into muscles or stromal keratocytes. CXCL14 may play an anti-angiogenic role (Shellenberger et al., 2004) by preventing $C X C L 12$-expressing angioblasts and ocular blood vessels from entering the developing cornea. Complementary expression of CXCL12 and CXCL14 in the anterior eye and hair follicles suggests that interaction of these genes might be essential during development. However, further studies to elucidate the functional role(s) of CXCL12 and CXCL14 during ocular development are required.

\section{EXPERIMENTAL PROCEDURES}

\subsection{Embryos}

All animal procedures were performed according to protocols approved by the Institutional Animal Care and Use Committee (IACUC) at Rice University. Fertilized White Leghorn chicken eggs (Gallus gallus domesticus) were obtained from a commercial supplier. Eggs were incubated at $38^{\circ} \mathrm{C}$ under humidified conditions. Chick embryos were collected between embryonic day (E)3 and E17. Wild-type C57/B6 mouse embryos were collected between E11.5 and E16.5, with the first appearance of a virginal plug considered as E0.5. Mouse eyes were also collected at postnatal day (P)0 and from adults. All tissues were collected in Ringer's solution, fixed overnight in modified Carnoy's fixative (60\% ethanol, 30\% formadehyde, and $10 \%$ glacial acetic acid) at $4{ }^{\circ} \mathrm{C}$. Tissues were dehydrated in ethanol series, cleared in Histosol and embedded in paraffin, then sectioned between 10 and $12 \mu \mathrm{m}$.

\subsection{Synthesis of mRNA riboprobes}

Fragments for $C X C L 14$ and $C X C L 12$ were amplified from chick and mouse embryo cDNA using PCR. Primers were used as follows: Gallus gallus CXCL14,

5'GATTCTCTAACGTACGGAAGC (forward) and 5'CCAGCATCACTCATGTACCTCT(reverse); Gallus gallus CXCL12, 5'TGGCTCTGCTCGCCTTTGC (forward) and 5'AAGTATCTGTGCTGGGGTCC (reverse); Mus musculus CXCL14, 5' ACTGCGAGGAGAAGATGGTTAT (forward) and 5' GTAGAAGATGCTTCTGAGGCATC (reverse); Mus musculus CXCL12, 5' GCCGCACTTTCACTCTCG (forward) and 5' GGTCATGCTAAGGTTTGCCA (reverse). The PCR products (750bp and 870bp for CXCL14, and 495bp and 500bp for CXCL12) were cloned into pCR®II-TOPO® vector with dual promoters (Invitrogen) following manufacture's protocol, and the gene inserts were confirmed by sequencing. Plasmids were linearized with EcoRV and or BamH1 and labeled riboprobes were generated using $\mathrm{T} 7$ or SP6 polymerases.

\subsection{In situ hybridization}

In situ hybridization was performed on sections as described previously (Etchevers et al., 2001). Sense probes were used as control, and showed no specific signal.

\subsection{Microscopy and imaging}

Images of stained sections were acquired using a Zeiss microscope and Axio Vision program (Carl Zeiss AG, Oberkochen, Germany) at 5X, 10X and 20X objectives.

\section{Acknowledgments}

We thank members of the Lwigale lab for discussions of the raw data and editing the early version of the manuscript. This work was supported by NIH grant EY022158 to PYL. 


\section{REFERENCES}

Agathocleous M, Harris WA. From progenitors to differentiated cells in the vertebrate retina. Annu. Rev. Cell Dev. Biol. 2009; 25:45-69. [PubMed: 19575661]

Banisadr G, Bhattacharyya BJ, Belmadani A, Izen SC, Ren D, Tran PB, Miller RJ. The chemokine BRAK/CXCL14 regulates synaptic transmission in the adult mouse dentate gyrus stem cell niche. J. Neurochem. 2011; 119:1173-1182. [PubMed: 21955359]

Barbaria EM, Kohl B, Buhren BA, Hasenpusch-Theil K, Kruse F, Küry P, Martini R, Müller HW. The alpha-chemokine CXCL14 is up-regulated in the sciatic nerve of a mouse model of Charcot-MarieTooth disease type 1A and alters myelin gene expression in cultured Schwann cells. Neurobiol. Dis. 2009; 33:448-458. [PubMed: 19111616]

Bassett EA, Wallace VA. Cell fate determination in the vertebrate retina. Trends Neurosci. 2012; 35:565-573. [PubMed: 22704732]

Belmadani A, Jung H, Ren D, Miller RJ. The chemokine SDF-1/CXCL12 regulates the migration of melanocyte progenitors in mouse hair follicles. Differentiation. 2009; 77:395-411. [PubMed: 19281787]

Chalasani SH, Baribaud F, Coughlan CM, Sunshine MJ, Lee VMY, Doms RW, Littman DR, Raper JA. The chemokine stromal cell-derived factor-1 promotes the survival of embryonic retinal ganglion cells. J. Neurosci. 2003; 23:4601-4612. [PubMed: 12805300]

Chen T, Bai H, Shao Y, Arzigian M, Janzen V, Attar E, Xie Y, Scadden DT, Wang ZZ. Stromal cellderived factor-1/CXCR4 signaling modifies the capillary-like organization of human embryonic stem cell-derived endothelium in vitro. Stem Cells. 2007; 25:392-401. [PubMed: 17038674]

Chow RL, Lang RA. Early eye development in vertebrates. Annu. Rev. Cell Dev. Biol. 2001; 17:255296. [PubMed: 11687490]

Coulombre AJ, Coulombre JL. The skeleton of the eye. I. Conjunctival papillae and scleral ossicles. Dev. Biol. 1962; 5:382-401. [PubMed: 14023393]

Creuzet S, Vincent C, Couly G. Neural crest derivatives in ocular and periocular structures. Int. J. Dev. Biol. 2005; 49:161-171. [PubMed: 15906229]

Cvekl A, Mitton KP. Epigenetic regulatory mechanisms in vertebrate eye development and disease. Heredity (Edinb). 2010; 105:135-151. [PubMed: 20179734]

Doh ST, Hao H, Loh SC, Patel T, Tawil HY, Chen DK, Pashkova A, Shen A, Wang H, Cai L. Analysis of retinal cell development in chick embryo by immunohistochemistry and in ovo electroporation techniques. BMC Dev. Biol. 2010; 10:8. [PubMed: 20089190]

Doitsidou M, Reichman-Fried M, Stebler J, Köprunner M, Dörries J, Meyer D, Esguerra CV, Leung T, Raz E. Guidance of primordial germ cell migration by the chemokine SDF-1. Cell. 2002; 111:647-659. [PubMed: 12464177]

Duench K, Franz-Odendaal TA. BMP and Hedgehog signaling during the development of scleral ossicles. Dev. Biol. 2012; 365:251-258. [PubMed: 22370003]

Franz-Odendaal TA, Vickaryous MK. Skeletal elements in the vertebrate eye and adnexa: morphological and developmental perspectives. Dev. Dyn. 2006; 235:1244-1255. [PubMed: 16496288]

Franz-Odendaal TA. Toward understanding the development of scleral ossicles in the chicken, Gallus gallus. Dev. Dyn. 2008; 237:3240-3251. [PubMed: 18855894]

Frick I-M, Nordin SL, Baumgarten M, Mörgelin M, Sørensen OE, Olin AI, Egesten A. Constitutive and inflammation-dependent antimicrobial peptides produced by epithelium are differentially processed and inactivated by the commensal Finegoldia magna and the pathogen Streptococcus pyogenes. J. Immunol. 2011; 187:4300-4309. [PubMed: 21918193]

Fuhrmann S. Eye morphogenesis and patterning of the optic vesicle. Curr. Top. Dev. Biol. 2010; 93:61-84. [PubMed: 20959163]

Funderburgh JL, Caterson B, Conrad GW. Keratan sulfate proteoglycan during embryonic development of the chicken cornea. Dev. Biol. 1986; 116:267-277. [PubMed: 2942429]

Gage PJ, Rhoades W, Prucka SK, Hjalt T. Fate maps of neural crest and mesoderm in the mammalian eye. Invest. Ophthalmol. Vis. Sci. 2005; 46:4200-4208. [PubMed: 16249499] 
García-Andrés C, Torres M. Comparative expression pattern analysis of the highly conserved chemokines SDF1 and CXCL14 during amniote embryonic development. Dev. Dyn. 2010; 239:2769-2777. [PubMed: 21038449]

Gordon CT, Wade C, Brinas I, Farlie PG. CXCL14 expression during chick embryonic development. Int. J. Dev. Biol. 2011; 55:335-340. [PubMed: 21710440]

Hall BK. Specificity in the differentiation and morphogenesis of neural crest-derived scleral ossicles and of epithelial scleral papillae in the eye of the embryonic chick. J Embryol Exp Morphol. 1981; 66:175-190. [PubMed: 7338710]

Hamburger V, Hamilton HL. A series of normal stages in the development of the chick embryo. 1951. Dev. Dyn. 1992; 195:231-272. [PubMed: 1304821]

Hara T, Tanegashima K. Pleiotropic functions of the CXC-type chemokine CXCL14 in mammals. J. Biochem. 2012; 151:469-476. [PubMed: 22437940]

Hasegawa T, McLeod DS, Prow T, Merges C, Grebe R, Lutty GA. Vascular precursors in developing human retina. Invest. Ophthalmol. Vis. Sci. 2008; 49:2178-2192. [PubMed: 18436851]

Hay ED, Linsenmayer TF, Trelstad RL, von der Mark K. Origin and distribution of collagens in the developing avian cornea. Curr Top Eye Res. 1979; 1:1-35. [PubMed: 400678]

Hay ED. Development of the vertebrate cornea. Int. Rev. Cytol. 1980; 63:263-322. [PubMed: 395131]

Hiasa, K-ichi; Ishibashi, M.; Ohtani, K.; Inoue, S.; Zhao, Q.; Kitamoto, S.; Sata, M.; Ichiki, T.; Takeshita, A.; Egashira, K. Gene transfer of stromal cell-derived factor-1alpha enhances ischemic vasculogenesis and angiogenesis via vascular endothelial growth factor/endothelial nitric oxide synthase-related pathway: next-generation chemokine therapy for therapeutic neovascularization. Circulation. 2004; 109:2454-2461. [PubMed: 15148275]

Hromas R, Broxmeyer HE, Kim C, Nakshatri H, Christopherson K, Azam M, Hou YH. Cloning of BRAK, a novel divergent CXC chemokine preferentially expressed in normal versus malignant cells. Biochem. Biophys. Res Commun (2nd). 1999; 255:703-706. [PubMed: 10049774]

Hunger C, Ödemis V, Engele J. Expression and function of the SDF-1 chemokine receptors CXCR4 and CXCR7 during mouse limb muscle development and regeneration. Exp. Cell Res. 2012; 318:2178-2190.

Ikoma T, Ozawa S, Suzuki K, Kondo T, Maehata Y, Lee MC-I, Hata R-I, Kubota E. Calciumcalmodulin signaling induced by epithelial cell differentiation upregulates BRAK/CXCL14 expression via the binding of SP1 to the BRAK promoter region. Biochem. Biophys. Res. Commun. 2012; 420:217-222. [PubMed: 22382027]

Johnston MC, Noden DM, Hazelton RD, Coulombre JL, Coulombre AJ. Origins of avian ocular and periocular tissues. Exp. Eye Res. 1979; 29:27-43. [PubMed: 510425]

Kasemeier-Kulesa JC, McLennan R, Romine MH, Kulesa PM, Lefcort F. CXCR4 controls ventral migration of sympathetic precursor cells. J. Neurosci. 2010; 30:13078-13088. [PubMed: 20881125]

Kiefer F, Siekmann AF. The role of chemokines and their receptors in angiogenesis. Cell. Mol. Life Sci. 2011; 68:2811-2830. [PubMed: 21479594]

Kurpakus MA, Maniaci MT, Esco M. Expression of keratins K12, K4 and K14 during development of ocular surface epithelium. Curr. Eye Res. 1994; 13:805-814. [PubMed: 7531631]

Kurth I, Willimann K, Schaerli P, Hunziker T, Clark-Lewis I, Moser B. Monocyte selectivity and tissue localization suggests a role for breast and kidney-expressed chemokine (BRAK) in macrophage development. J. Exp. Med. 2001; 194:855-861. [PubMed: 11561000]

Kwiatkowski S, Munjaal RP, Lee T, Lwigale PY. Expression of pro-and anti-angiogenic factors during the formation of the periocular vasculature and development of the avian cornea. 2013

Lazarini F, Tham TN, Casanova P, Arenzana-Seisdedos F, Dubois-Dalcq M. Role of the alphachemokine stromal cell-derived factor (SDF-1) in the developing and mature central nervous system. Glia. 2003; 42:139-148. [PubMed: 12655598]

Li M, Ransohoff RM. Multiple roles of chemokine CXCL12 in the central nervous system: a migration from immunology to neurobiology. Prog. Neurobiol. 2008; 84:116-131. [PubMed: 18177992]

Lwigale PY, Cressy PA, Bronner-Fraser M. Corneal keratocytes retain neural crest progenitor cell properties. Dev. Biol. 2005; 288:284-293. [PubMed: 16263107] 
Long Q, Quint E, Lin S, Ekker M. The zebrafish scyba gene encodes a novel CXC-type chemokine with distinctive expression patterns in the vestibulo-acoustic system during embryogenesis. Mech. Dev. 2000; 97:183-186. [PubMed: 11025222]

Ma Q, Jones D, Borghesani PR, Segal RA, Nagasawa T, Kishimoto T, Bronson RT, Springer TA. Impaired B-lymphopoiesis, myelopoiesis, and derailed cerebellar neuron migration in CXCR4and SDF-1-deficient mice. Proc. Natl. Acad. Sci. U.S.A. 1998; 95:9448-9453. [PubMed: 9689100]

Meuter S, Schaerli P, Roos RS, Brandau O, Bösl MR, von Andrian UH, Moser B. Murine CXCL14 is dispensable for dendritic cell function and localization within peripheral tissues. Mol. Cell. Biol. 2007; 27:983-992. [PubMed: 17130243]

Meuter S, Moser B. Constitutive expression of CXCL14 in healthy human and murine epithelial tissues. Cytokine. 2008; 44:248-255. [PubMed: 18809336]

Murray PD. The development of the conjunctival papillae and of the scleral bones in the embryo chick. J. Anat. 1943; 77:225-240. 2. [PubMed: 17104928]

Nagasawa T, Hirota S, Tachibana K, Takakura N, Nishikawa S, Kitamura Y, Yoshida N, Kikutani H, Kishimoto T. Defects of B-cell lymphopoiesis and bone-marrow myelopoiesis in mice lacking the CXC chemokine PBSF/SDF-1. Nature. 1996; 382:635-638. [PubMed: 8757135]

Nara N, Nakayama Y, Okamoto S, Tamura H, Kiyono M, Muraoka M, Tanaka K, Taya C, Shitara H, Ishii R, et al. Disruption of CXC motif chemokine ligand-14 in mice ameliorates obesity-induced insulin resistance. J. Biol. Chem. 2007; 282:30794-30803. [PubMed: 17724031]

Narayanan $\mathrm{CH}$, Narayanan Y. Determination of the embryonic origin of the mesencephalic nucleus of the trigeminal nerve in birds. J Embryol Exp Morphol. 1978; 43:85-105. [PubMed: 632745]

Noden DM. Patterning of avian craniofacial muscles. Dev. Biol. 1986; 116:347-356. [PubMed: 3732610]

Olesnicky Killian EC, Birkholz DA, Artinger KB. A role for chemokine signaling in neural crest cell migration and craniofacial development. Dev. Biol. 2009; 333:161-172. [PubMed: 19576198]

Park B-Y, Hong C-S, Sohail FA, Saint-Jeannet J-P. Developmental expression and regulation of the chemokine CXCL14 in Xenopus. Int. J. Dev. Biol. 2009; 53:535-540. [PubMed: 19488965]

Park CR, Kim D-K, Cho EB, You D-J, do Rego JL, Vaudry D, Sun W, Kim H, Seong JY, Hwang J-I. Spatiotemporal expression and functional implication of CXCL14 in the developing mice cerebellum. Mol. Cells. 2012; 34:289-293. [PubMed: 22843118]

Pei YF, Rhodin JA. The prenatal development of the mouse eye. Anat. Rec. 1970; 168:105-125. [PubMed: 5469558]

Pinto CB, Hall BK. Toward an understanding of the epithelial requirement for osteogenesis in scleral mesenchyme of the embryonic chick. J. Exp. Zool. 1991; 259:92-108. [PubMed: 1906525]

Rehimi R, Khalida N, Yusuf F, Dai F, Morosan-Puopolo G, Brand-Saberi B. Stromal-derived factor-1 (SDF-1) expression during early chick development. Int. J. Dev. Biol. 2008; 52:87-92. [PubMed: 18033676]

Rostène W, Kitabgi P, Parsadaniantz SM. Chemokines: a new class of neuromodulator? Nat. Rev. Neurosci. 2007; 8:895-903. [PubMed: 17948033]

Schaerli P, Willimann K, Ebert LM, Walz A, Moser B. Cutaneous CXCL14 targets blood precursors to epidermal niches for Langerhans cell differentiation. Immunity. 2005; 23:331-342. [PubMed: 16169505]

Schlötzer-Schrehardt U, Kruse FE. Identification and characterization of limbal stem cells. Exp. Eye Res. 2005; 81:247-264. [PubMed: 16051216]

Shellenberger TD, Wang M, Gujrati M, Jayakumar A, Strieter RM, Burdick MD, Ioannides CG, Efferson CL, El-Naggar AK, Roberts D, et al. BRAK/CXCL14 is a potent inhibitor of angiogenesis and a chemotactic factor for immature dendritic cells. Cancer Res. 2004; 64:82628270. [PubMed: 15548693]

Sierro F, Biben C, Martínez-Muñoz L, Mellado M, Ransohoff RM, Li M, Woehl B, Leung H, Groom J, Batten M, et al. Disrupted cardiac development but normal hematopoiesis in mice deficient in the second CXCL12/SDF-1 receptor, CXCR7. Proc. Natl. Acad. Sci. U.S.A. 2007; 104:1475914764. [PubMed: 17804806] 
Spradling A, Drummond-Barbosa D, Kai T. Stem cells find their niche. Nature. 2001; 414:98-104. [PubMed: 11689954]

Stebler J, Spieler D, Slanchev K, Molyneaux KA, Richter U, Cojocaru V, Tarabykin V, Wylie C, Kessel M, Raz E. Primordial germ cell migration in the chick and mouse embryo: the role of the chemokine SDF-1/CXCL12. Dev. Biol. 2004; 272:351-361. [PubMed: 15282153]

Stibbe EP. A Comparative Study of the Nictitating Membrane of Birds and Mammals. J. Anat. 1928; 62:159-176. [PubMed: 17104180]

Tanegashima K, Okamoto S, Nakayama Y, Taya C, Shitara H, Ishii R, Yonekawa H, Minokoshi Y, Hara T. CXCL14 deficiency in mice attenuates obesity and inhibits feeding behavior in a novel environment. PLoS ONE. 2010; 5:e10321. [PubMed: 20428232]

Tanifuji-Terai N, Terai K, Hayashi Y, Chikama T-ichiro, Kao WW-Y. Expression of keratin 12 and maturation of corneal epithelium during development and postnatal growth. Invest. Ophthalmol. Vis. Sci. 2006; 47:545-551. [PubMed: 16431949]

Theveneau E, Marchant L, Kuriyama S, Gull M, Moepps B, Parsons M, Mayor R. Collective chemotaxis requires contact-dependent cell polarity. Dev. Cell. 2010; 19:39-53. [PubMed: 20643349]

Tseng SC. Concept and application of limbal stem cells. Eye (Lond). 1989; 3(Pt 2):141-157. [PubMed: 2695347]

Vasyutina E, Stebler J, Brand-Saberi B, Schulz S, Raz E, Birchmeier C. CXCR4 and Gab1 cooperate to control the development of migrating muscle progenitor cells. Genes Dev. 2005; 19:2187-2198. [PubMed: 16166380]

Venters SJ, Cuenca PD, Hyer J. Retinal and anterior eye compartments derive from a common progenitor pool in the avian optic cup. Mol. Vis. 2011; 17:3347-3363. [PubMed: 22219630]

Wang X, Tredget EE, Wu Y. Dynamic signals for hair follicle development and regeneration. Stem Cells Dev. 2012; 21:7-18. [PubMed: 21787229]

Wedlock DE, McCallion DJ. Induction of scleral cartilage in the chorioallantois of the chick embryo. Can. J. Zool. 1969; 47:142-143. [PubMed: 5406765]

Wong MM, Fish EN. Chemokines: attractive mediators of the immune response. Semin. Immunol. 2003; 15:5-14. [PubMed: 12495636]

Yamaguchi, J-ichi; Kusano, KF.; Masuo, O.; Kawamoto, A.; Silver, M.; Murasawa, S.; Bosch-Marce, M.; Masuda, H.; Losordo, DW.; Isner, JM., et al. Stromal cell-derived factor-1 effects on ex vivo expanded endothelial progenitor cell recruitment for ischemic neovascularization. Circulation. 2003; 107:1322-1328. [PubMed: 12628955]

Yusuf F, Rehimi R, Moroşan-Puopolo G, Dai F, Zhang X, Brand-Saberi B. Inhibitors of CXCR4 affect the migration and fate of CXCR4+ progenitors in the developing limb of chick embryos. Dev. Dyn. 2006; 235:3007-3015. [PubMed: 16958136]

Zieske JD. Corneal development associated with eyelid opening. Int. J. Dev. Biol. 2004; 48:903-911. [PubMed: 15558481]

Zou YR, Kottmann AH, Kuroda M, Taniuchi I, Littman DR. Function of the chemokine receptor CXCR4 in haematopoiesis and in cerebellar development. Nature. 1998; 393:595-599. [PubMed: 9634238] 


\section{Highlights}

- $\quad C X C L 12$ is predominantly expressed in ocular mesenchyme-derived tissues, blood vessels, and retina, and it is mostly conserved between chick and mouse.

- $\quad$ CXCL14 is expressed in the ocular ectoderm, limbal epithelium, scleral papillae, eyelid mesenchyme, corneal keratocytes, hair follicles, and retina.

- Expression of CXCL14 is only conserved in the outer eyelid ectoderm of chick and mouse.

- Non-overlapping expression profiles of CXCL12 and CXCL14 are consistent with their potential interaction and functions in cell proliferation, differentiation, and migration during ocular development. 


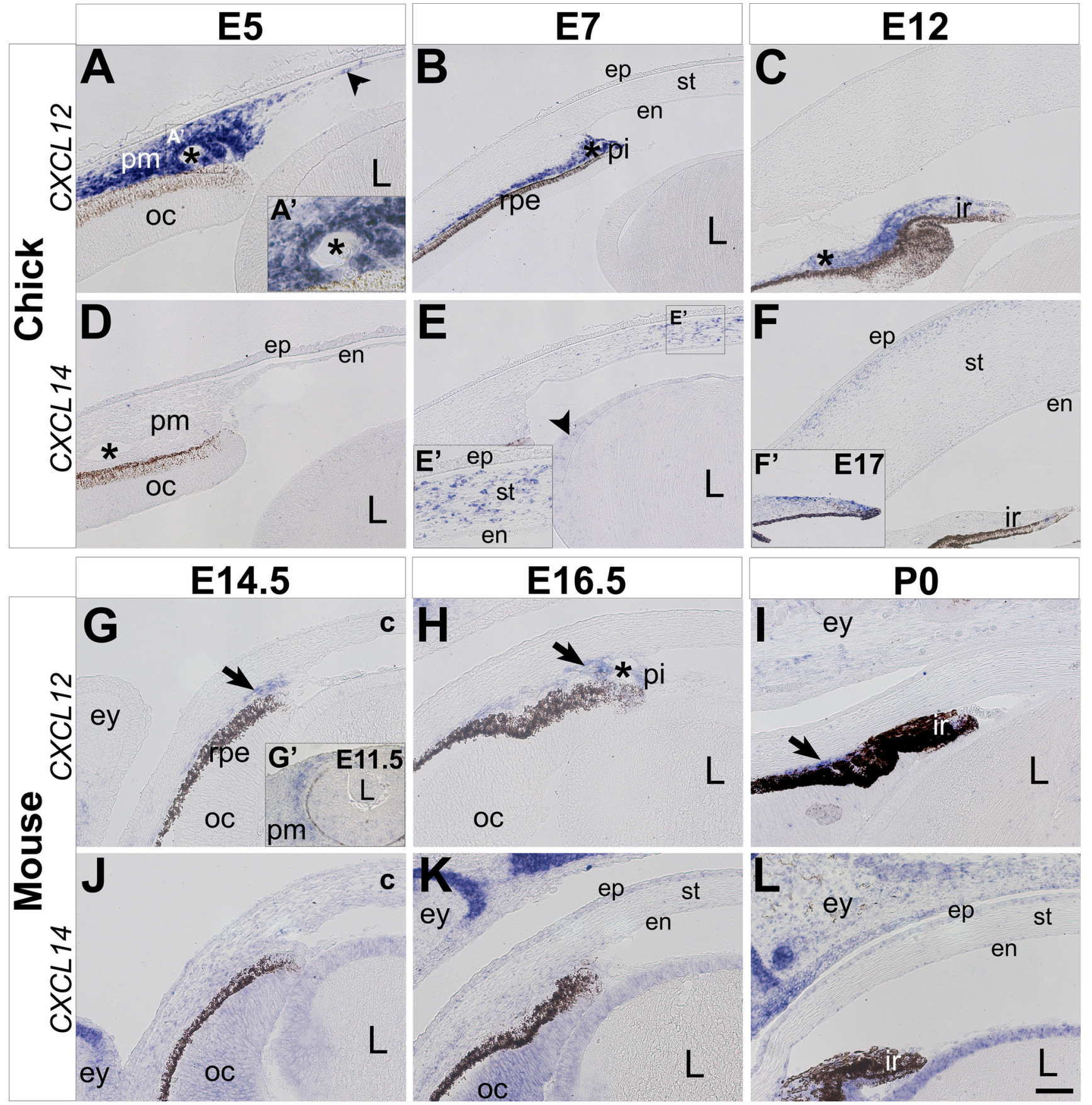

Figure 1. Expression of $C X C L 12$ and $C X C L 14$ during development of the cornea and iris in chick and mouse

In situ hybridization was performed on paraffin sections through the anterior eye of chick and mouse embryos. (A-F) During chick eye development, CXCL12 is strongly expressed in the periocular mesenchyme and its derivatives between E5 and E12 (A-C). CXCL14 expression is not detected in the periocular region and presumptive cornea at E5 (D), but it is later expressed in the cornea, lens, and iris between E7-E17 (E-F). (G-L) During mouse eye development, $C X C L 12$ is expressed in the periocular mesenchyme and its derivatives between E11.5 and P0 (G-I). CXCL14 is initially expressed at low levels at E14.5 (J), and then it becomes restricted to the cornea epithelium, optic cup, and lens epithelium between 
E16.5 and P0 (K-L). Asterisks in A-D and H indicate ocular blood vessels; c, cornea; en, cornea endothelium; ep, cornea epithelium; ey, eyelid; ir, iris; L, lens; oc, optic cup; pi, presumptive iris; pm, periocular mesenchyme; rpe, retinal pigmented epithelium; st, cornea stroma. Scale bar represents $100 \mu \mathrm{m}$ in B, C, E, and F and $50 \mu \mathrm{m}$ in A, D, G-L. 


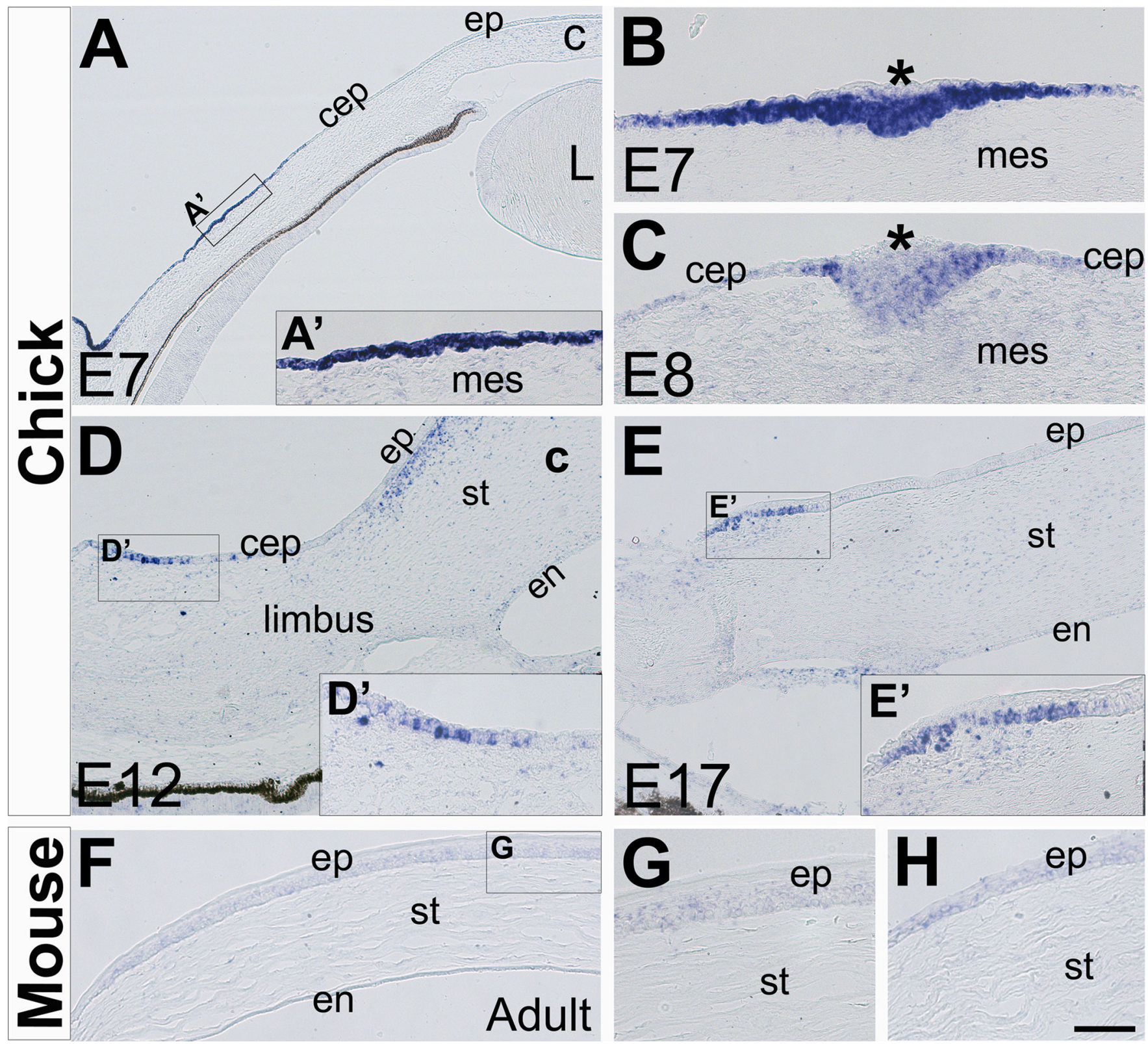

Figure 2. Expression of $C X C L 14$ in the developing chick conjunctival epithelium and adult mouse cornea epithelium

(A-E) Expression of CXCL14 in the chick conjunctival epithelium (A-C) during formation of the scleral papillae between E7 and E8 chick eye development, and (D-E) in the limbal epithelium at E12 and E17. (F-G) Expression of $C X C L 14$ in the adult mouse cornea epithelium in the central $(\mathrm{G})$ and peripheral $(\mathrm{H})$ regions. Asterisks in B and E indicate superficial cells of the scleral papillae; c, cornea; cep, conjunctival epithelium; en, cornea endothelium; ep, cornea epithelium; L; lens; mes, mesenchyme; st, cornea stroma. Scale bar represents $200 \mu \mathrm{m}$ in $\mathrm{A}, 100 \mu \mathrm{m}$ in $\mathrm{D}, \mathrm{E}$ and $\mathrm{F}$, and $50 \mu \mathrm{m}$ in $\mathrm{B}, \mathrm{C}, \mathrm{G}$ and $\mathrm{H}$. 


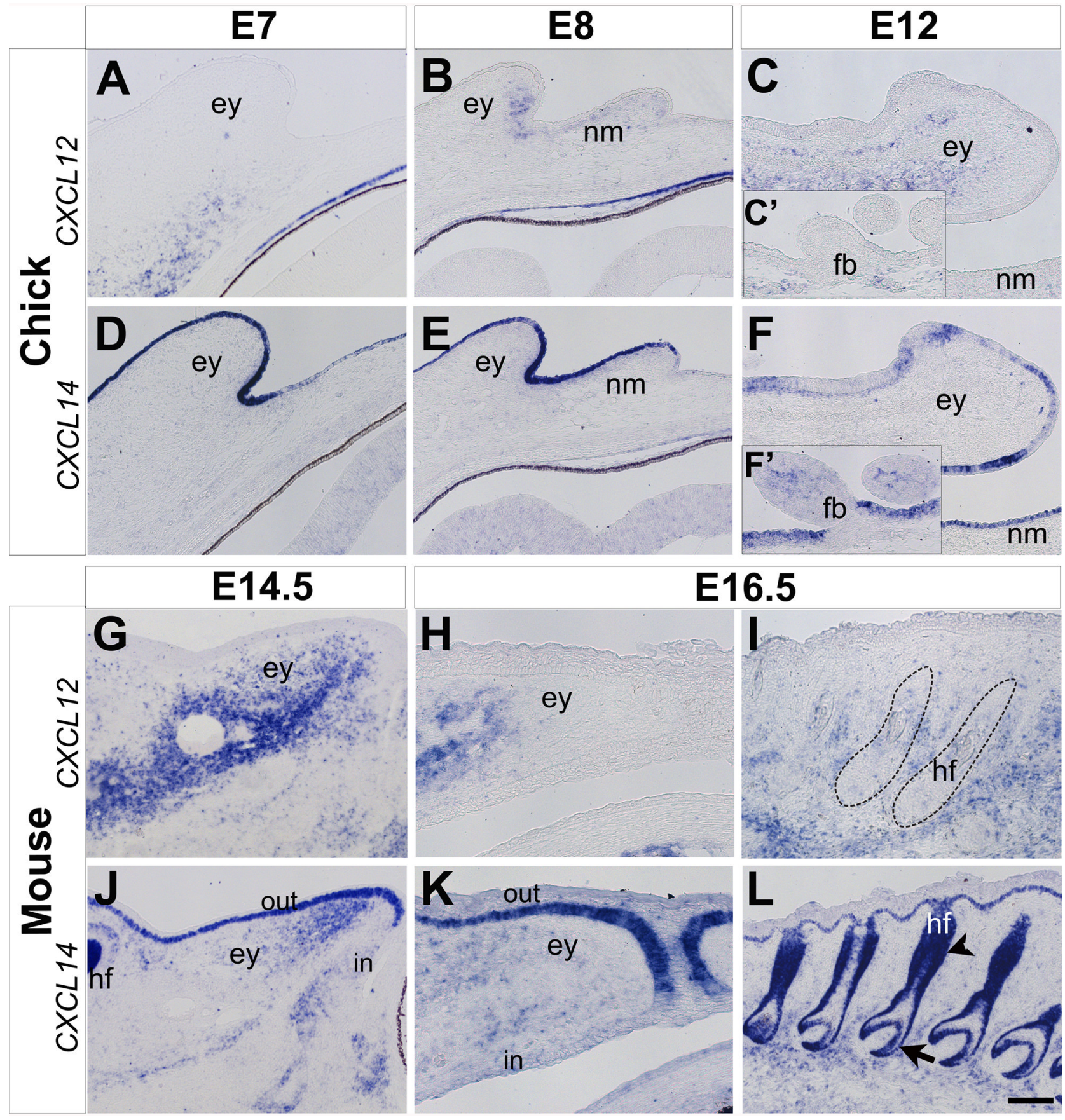

Figure 3. Expression of $C X C L 12$ and $C X C L 14$ during eyelid development in chick and mouse (A-F) Expression of CXCL12 (A-C) and CXCL14 (D-F) during chick eyelid development. CXCL12 is initially not expressed in the eyelid at E7 (A), but it becomes prominent between E8 and E12 (B-C). Expression of CXCL12 is absent in the feather buds (C'). Expression of CXCL14 is robust in the ectoderm of the eyelids and nictitating membrane between E7-E12 (D-F), but not continuous in the feather buds where it is expressed in the mesenchyme (F'). $(\mathbf{G}-\mathbf{L})$ Expression of $C X C L 12(\mathrm{G}-\mathrm{I})$ and $C X C L 14(\mathrm{~J}-\mathrm{L})$ during eyelid and hair follicle development in the mouse. $C X C L 12$ is strongly expressed in the eyelid mesenchyme between E14.5- E16.5 ( $\mathrm{G}$ and H). CXCL12 is also expressed in the mesenchyme 
surrounding the hair follicles (I, dotted outline). CXCL14 is expressed in the eyelid ectoderm and mesenchyme between E14.5 and E16.5 ( $\mathrm{J}$ and K), and in the hair follicles (L). ey, eyelid; nm, nictitating membrane; fb, feather buds; hf, hair follicle; in, inner eyelid epithelium; out, outer eyelid epithelium. Scale bar represents $100 \mu \mathrm{m}$ in B, C, E, F, I, and L, and $50 \mu \mathrm{m}$ in $\mathrm{A}, \mathrm{D}, \mathrm{G}, \mathrm{H}, \mathrm{J}$, and $\mathrm{K}$. 




Figure 4. Expression of $C X C L 12$ and $C X C L 14$ during retina development in chick and mouse (A-D) Expression of CXCL12 (A and B) and CXCL14 (C and D) in the chick retina at E7 and E12. (E-F) Expression of CXCL12 (E and F) and CXCL14 (G and H) in the mouse retina at E16.5, P0, and young adult (H'). gcl, ganglion cell layer; inl, inner nuclear layer; ipl, inner plexiform layer; nr, neural retina; rpe, retinal pigmented epithelium. Scale bar represents $50 \mu \mathrm{m}$. 